\title{
A case of acute calcium pyrophosphate arthritis in two rare sites of involvement: The cervical facet and atlantoaxial joint
}

\author{
Suzan Saylısoy (i) \\ Department of Radiology, Eskişehir Osmangazi University, Faculty of Medicine, Eskişehir, Turkey
}

The crystal arthropathies including hydroxyapatite crystal deposition disease (HADD), calcium pyrophosphate dihydrate deposition (CPPD) disease, and monosodium urate crystals (gout) in which crystals are deposited in the joints and/or soft tissues lead to a variety of articular and periarticular disorders. ${ }^{[1]}$ Acute CPPD arthritis is the most notable manifestation of CPPD disease, while CPPD can also result in asymptomatic disease or chronic CPPD arthropathies. ${ }^{[2]}$

The CPPD disease usually occurs in the major joints such as the knee, hip, wrist, and pubic symphysis. ${ }^{[3]}$ However, CPPD disease in the spine is a rare entity. ${ }^{[4-9]}$ This article describes the case of a patient with neck pain who was diagnosed as CPPD of the atlantoaxial joint and right $\mathrm{C} 4-\mathrm{C} 5$ facet joint with radiological findings.

\section{CASE REPORT}

A 67-year-old female patient presented with one-month history of neck pain exacerbated by movement. On clinical examination, there was no motor weakness or sensory deficit. The patient was

Received: February 17, 2020

Accepted: April 06, 2020

Published online: June 18, 2020

Correspondence: Suzan Saylısoy, MD. Eskișehir Osmangazi Üniversitesi Tıp Fakültesi Radyoloji Anabilim Dalı, 26040 Meşelik, Eskisehir, Türkiye.

E-mail: sunasel06@yahoo.com

Doi: $10.5606 /$ ehc. 2020.74329

Citation: Saylisoy S. A case of acute calcium pyrophosphate arthritis in two rare sites of involvement: The cervical facet and atlantoaxial joint. Jt Dis Relat Surg 2020;31(2):395-398.

\section{ABSTRACT}

Calcium pyrophosphate dihydrate deposition (CPPD) disease, also known as pseudogout, in which crystals are deposited in the joints and/or soft tissues, leads to a variety of articular and periarticular disorders. Herein we report a 67-year-old female patient with neck pain who was diagnosed as CPPD disease of both the atlantoaxial joint and right C4-C5 facet joint with radiological findings. The combined use of computed tomography and magnetic resonance imaging can be helpful in establishing a diagnosis and providing the correct treatment.

Keywords: Atlantoaxial joint, calcium pyrophosphate dihydrate, facet joint, magnetic resonance imaging.

afebrile. On laboratory examination, the patient had normal hemoglobin levels, normal liver function test results, and normal results on uric acid, calcium, phosphorus, and urine analyses. Her erythrocyte sedimentation rate (ESR) was $15 \mathrm{~mm} /$ hour (normal, 0-10 $\mathrm{mm} /$ hour) and C-reactive protein (CRP) increased to $3 \mathrm{mg} / \mathrm{dL}$ (normal, $0-0.3 \mathrm{mg} / \mathrm{dL}$ ). A written informed consent was obtained from the patient.

Magnetic resonance imaging (MRI) showed marrow edema within the dens, anterior arch of $\mathrm{C} 1$ and pathological contrast enhancement at periarticular soft tissue (Figure 1a-d). Computed tomography (CT) revealed periodontoid calcified deposits suggesting CPPD (Figure 1e). Magnetic resonance imaging also demonstrated bone marrow edema on C4-5 facet joint and perivertebral signal alteration adjacent to the facet joint (Figure 2). The patient was diagnosed as CPPD disease and started systemic antiinflammatory treatment (oral colchicine). At one-year follow-up, the neck pain gradually improved. 

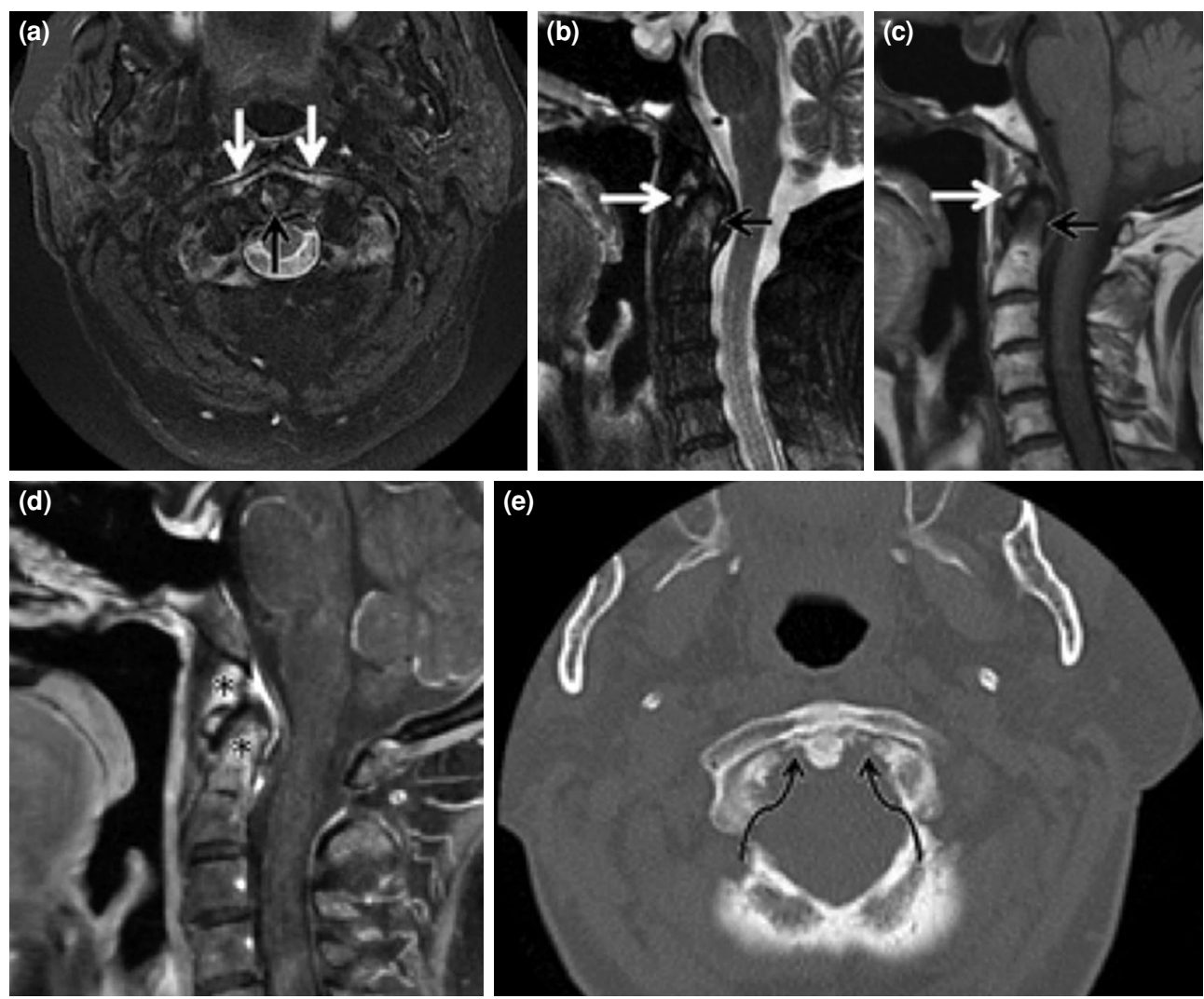

FIGURE 1. (a) Axial fat-saturated T2-weighted, (b) sagittal fat-saturated T2-weighted, (c) sagittal T1-weighted images show bone marrow edema within anterior arch of $\mathrm{C} 1$ (white arrows) and dens (black arrows). (d) Sagittal post-contrast, fat-saturated T1-weighted image reveals pathological enhancement at periarticular soft tissue and dens (asterisks). (e) Axial computed tomography shows high attenuation deposits around odontoid process (curved arrows).
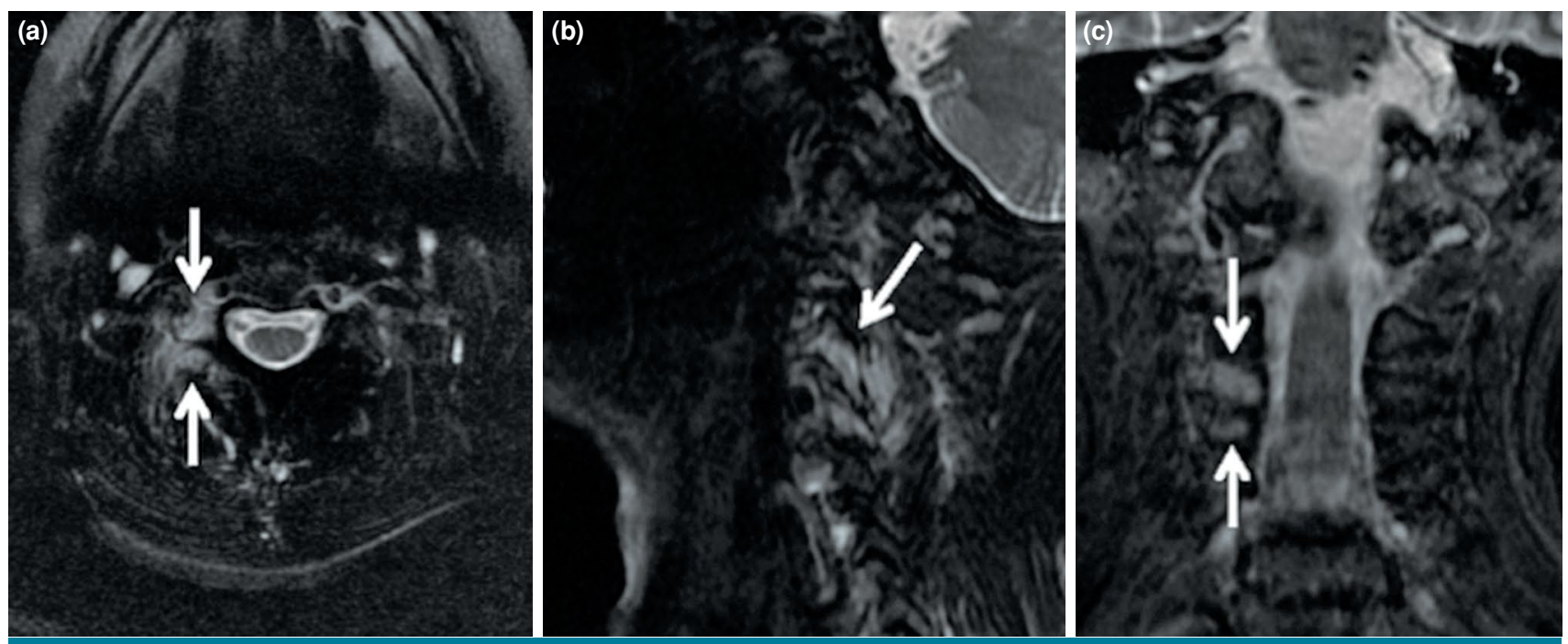

FIGURE 2. (a) Axial fat-saturated T2-weighted, (b) sagittal fat-saturated T2-weighted, (c) coronal short-tau inversion-recovery images show edema on C4-5 facet joints and perivertebral signal alteration adjacent to right $\mathrm{C} 4-5$ facet joint suggesting calcium pyrophosphate dihydrate deposition (arrows). 


\section{DISCUSSION}

Calcium pyrophosphate dihydrate deposition disease, also known as pseudogout, is among many conditions that may result in crystal deposition in the joints and/or soft tissues. The incidence of CPPD disease increases with age, up to $45 \%$ for people 85 years of age or older. ${ }^{[2]}$ The idiopathic CPDD is the most common form of the CPPD disease. Calcium pyrophosphate dihydrate deposition disease can be associated with metabolic or endocrine disease including hyperparathyroidism, hemochromatosis, hypothyroidism, Wilson's disease, and hypophosphatasia. Hereditary forms of the disease have also been reported. ${ }^{[1]}$

The CPPD disease commonly involves the knee, hip, wrist and pubic symphysis. ${ }^{[3]}$ However, there are very few reports in the literature of CPPD in the spine. ${ }^{[4-9]}$ Calcium pyrophosphate dihydrate deposition crystals may be found in several spinal structures including the ligamentum flavum, posterior longitudinal ligament, atlanto-occipital ligament, joint capsules, synovium, articular cartilage and the intervertebral discs. ${ }^{[4]}$ Calcium pyrophosphate dihydrate deposition in the atlantoaxial joint leads to erosive and destructive changes with atlantoaxial subluxation in some patients. Calcium pyrophosphate dihydrate deposition in the periodontoid region may cause ventral cervicomedullary compression. The calcification surrounding the dens is termed crowned dens syndrome. ${ }^{[1,11]}$ The facet joints are also affected. ${ }^{[4-9]}$ Calcium pyrophosphate dihydrate deposition can be a cause of symptomatic spinal stenosis associated with cyst formation in a facet joint. ${ }^{[5-7]}$ Moreover, CPPD within the ligaments can be associated with spinal stenosis. ${ }^{[1]}$

Acute CPPD arthritis of cervical region may result in acute neck pain and tenderness. Laboratory findings may show increased ESR and high CRP levels. The inorganic pyrophosphate levels in serum and urine are normal in patients with CPPD disease, although nonspecific, inorganic pyrophosphate levels may be elevated in the synovial fluid of affected joints. ${ }^{[2,11]}$

Differential diagnosis of CPPD includes osteoarthritis, spinal infections including bacterial and fungal infections, other crystal artropathies including gout and HADD, and other inflammatory diseases such as rheumatoid arthritis, scleroderma, and malignancy. ${ }^{[1,2,11]}$

Imaging including radiographs, CT and MRI is useful for the initial diagnosis and the follow-up after treatment. ${ }^{[1,2]}$ Cervical spine radiographs provide a quick and general overview, while the analysis of the craniovertebral junction and upper cervical spine is often difficult on the radiographs. Computed tomography is the best technique to detect calcific deposits in cartilage and soft tissue, suggesting CPPD. Magnetic resonance imaging shows bone marrow edema, soft-tissue changes, and fluid effusions. Gadolinium-enhanced images are useful to assess inflammatory bony changes and articular synovitis, and to rule out the presence of an infectious spinal collection. $^{[1,4]}$ The combining use of CT and MRI improves diagnostic accuracy of spinal CPPD.

Previous studies related with cervical CPPD have generally focused on CPPD in the joints and periarticular tissues and have emphasized that $\mathrm{CT}$ is superior to MRI in confirming CPPD. ${ }^{[12-14]}$ Moshrif et al. ${ }^{[12]}$ reported imaging features of spinal involvement including calcifications and aseptic spondylodiscitis in 37 patients out of a series of 152 patients with peripheral joint CPPD. In a series reported by Finckh et al., ${ }^{[13]}$ cervical calcifications were found in 24 out of 35 patients diagnosed with peripheral joint CPPD. In a study including 14 patients with CPPD disease of the cervical spine, Sekijima et al. ${ }^{[14]}$ reported calcific deposits in periodontoid structures and the ligamenta flava. Although MRI is poorly sensitive to detect calcifications, it is successful in revealing perivertebral and periarticular marrow signal abnormalities as in this case. Magnetic resonance imaging shows periarticular bone marrow edema and perivertebral inflammation in two different areas related to acute attack in this case.

In conclusion, CPPD disease of the servical spine is rare, while this clinical entity should be added to the differential diagnosis of neck pain. Utilization of imaging techniques including CT and MRI can be helpful in establishing a diagnosis and providing the correct treatment.

\section{Declaration of conflicting interests}

The author declared no conflicts of interest with respect to the authorship and/or publication of this article.

\section{Funding}

The author received no financial support for the research and/or authorship of this article.

\section{REFERENCES}

1. Steinbach LS, Resnick D. Calcium pyrophosphate dihydrate crystal deposition disease revisited. Radiology 1996;200:1-9.

2. McCarthy GM, Dunne A. Calcium crystal deposition diseases - beyond gout. Nat Rev Rheumatol 2018;14:592-602.

3. Magarelli N, Amelia R, Melillo N, Nasuto M, Cantatore F, Guglielmi G. Imaging of chondrocalcinosis: calcium 
pyrophosphate dihydrate (CPPD) crystal deposition disease -- imaging of common sites of involvement. Clin Exp Rheumatol 2012;30:118-25.

4. Feydy A, Lioté F, Carlier R, Chevrot A, Drapé JL. Cervical spine and crystal-associated diseases: imaging findings. Eur Radiol 2006;16:459-68.

5. Fujishiro T, Nabeshima Y, Yasui S, Fujita I, Yoshiya S, Fujii H. Pseudogout attack of the lumbar facet joint: a case report. Spine (Phila Pa 1976) 2002;27:E396-8.

6. Namazie MR, Fosbender MR. Calcium pyrophosphate dihydrate crystal deposition of multiple lumbar facet joints: a case report. J Orthop Surg (Hong Kong) 2012;20:254-6.

7. Mahmud T, Basu D, Dyson PH. Crystal arthropathy of the lumbar spine: a series of six cases and a review of the literature. J Bone Joint Surg [Br] 2005;87:513-7.

8. Omura K, Hukuda S, Matsumoto K, Katsuura A, Nishioka J, Imai S. Cervical myelopathy caused by calcium pyrophosphate dihydrate crystal deposition in facet joints. A case report. Spine (Phila Pa 1976) 1996;21:2372-5.

9. Turaga S, Thomas M, Savy L, Schreiber BE. Pseudogout or pseudolymphoma? Calcium pyrophosphate deposition disease of the cervical spine: a rare presentation and literature review. BMJ Case Rep 2019;12:e231508.

10. Atik OŞ. Which articles do we prefer to publish? Eklem Hastalik Cerrahisi 2018;29:1.

11. Ivory D, Velázquez CR. The forgotten crystal arthritis: calcium pyrophosphate deposition. Mo Med 2012;109:64-8.

12. Moshrif A, Laredo JD, Bassiouni H, Abdelkareem M, Richette P, Rigon MR, et al. Spinal involvement with calcium pyrophosphate deposition disease in an academic rheumatology center: A series of 37 patients. Semin Arthritis Rheum 2019;48:1113-26.

13. Finckh A, Van Linthoudt D, Duvoisin B, Bovay P, Gerster JC. The cervical spine in calcium pyrophosphate dihydrate deposition disease. A prevalent case-control study. J Rheumatol 2004;31:545-9.

14. Sekijima Y, Yoshida T, Ikeda S. CPPD crystal deposition disease of the cervical spine: a common cause of acute neck pain encountered in the neurology department. J Neurol Sci 2010;296:79-82. 